\title{
Analysis of research on the impact of electromagnetic fields and the degree of their automation
}

\author{
Nikolay Filippenko ${ }^{1, *}$, Alexandr Lipchitz ${ }^{1}$, and Sergey Kargapoltzev ${ }^{1}$ \\ ${ }^{1}$ Irkutsk State Transport University, 634076 Irkutsk, Russia
}

\begin{abstract}
In spite of the significant amount of scientific publications on the impact of fields on structural properties of nonmagnetic materials, investigations of structures of materials subjected to electromagnetic actions are relevant. The purpose of the paper is review and analysis of the state-of-the-art developments on the impact of electromagnetic fields that differ in power and nature. Analysis of the studied outputs enabled to conclude that direct contactless inertia-free effect on the material structure and dynamics of its defects at various levels. It was defined that the use of automated systems of research process management is difficult.
\end{abstract}

\section{Introduction}

Competitiveness and reliability of machines and mechanisms is a vital task of modern industry. Its solution is based on research of methods that enable to create a structure with specified physical and mechanical properties, which is possible due to the fields of different nature. the goal of this article is the analysis of scientific and practical information in the field of the modification of various materials with the help of electric and magnetic fields and methods for their control.

Modern studies in the domain of electromagnetic fields and their effects [1-8] confirm that with the help of low-power fields, a direct contactless effect on the structure of the material and the dynamics of its defects at various levels is possible. They also ave strong effect on the dynamics of various defects in structural materials. Such active impact of fields results in a change in the macroproperties of the material and the operational properties of the product [9]. In a number of works [10-12] it is noted that processing by electromagnetic fields (EMF) is characterized by low energy costs. Thus, for example, typical energy values transmitted to one atom in a crystal lattice with some parameter a in commonly used fields are the following magnitudes in sequence:

in magnetic field (MF)

$$
\Delta \mathrm{W} \approx \mu_{\mathrm{B}} B \approx 10^{-4}{ }_{\ni} B
$$

in electric field $(\mathrm{EF})$

$$
\Delta \mathrm{W} \approx e E a \approx 10^{-4}{ }_{\ni} B
$$

\footnotetext{
*Corresponding author: ifpi@mail.ru
} 
in pulse current field

in force field under deformation

$$
\Delta \mathrm{W} \approx j^{2} \rho a^{3} \approx 10^{-4}{ }_{\ni} B
$$

and thermal field

$$
\Delta \mathrm{W} \approx E^{\prime} \varepsilon^{2} a^{3} \approx 10^{-3}{ }{ }^{B}
$$

$$
\Delta T=100 K, \Delta W \approx k T \approx 10^{-2} \ni B
$$

Here: $\mu$ is the Bohr magneton, $\mathrm{e}$ is the elementary charge, $\rho$ is the specific resistivity, $\mathrm{k}$ is the Boltzmann constant, $\mathrm{E}$ is the energy, $\mathrm{E}^{\prime}$ is Young's modulus.

In any real material, defects reduce the degree of its symmetry, locally redistribute the electron density, which causes the emergence of long-range macroscopic electric and magnetic fields [9]. In ideal material, EF and MF can cause ordering in dipole and magnetic moments and phase transitions. Point defects and their interaction with dislocations are an important factor. For example, if a defect has a dipole or magnetic moment and an elastic anisotropy, its orientation in the EF and MF will cause a decrease in the flow stress in some planes and an increase in others. In metals, the change in the state of the electron gas in EF and MF can affect the plastic properties due to the effect of electron-dislocation interaction. The nature of the interaction between dislocations and fields depends on the nature of the field: the EF can exert a force action on the charged dislocation cores, and the non-uniform MF can exert a force action on the particles possessing a magnetic moment. Dislocations in various crystals (ionic, covalent, metallic) cause an increased magnetic susceptibility [9$10]$.

As for the effect of EMF on macrodefects and the sample as a whole, the difference in the density of EMF energy in adjacent elementary volumes of the sample or on the surface causes the emergence of electrodynamic forces. It shall be noted that the flowing current causes warming up, which leads to the emergence of thermal influences and stresses.

In addition, a number of related phenomena that have been reduced to a significant influence of MF on various physical and mechanical and other characteristics of nonmagnetic materials have been found.

Great attention was immediately paid to the work of V.I. Alshits with his colleagues [11]. It described a contradictory phenomenon, at first glance: the stimulation of the motion of dislocations in $\mathrm{NaCl}$ single crystals. The action was introduced by a weak impact of a constant MP. Further studies in this field have shown that the magnetoplastic effect leads to a decrease in the yield point, a decrease in the microhardness and internal friction of various single-crystal materials.

According to [12], some effects (EMF) manifest themselves under EMF action only, whereas others can be reversible and irreversible (Fig. 1). It is assumed that nonequilibrium in the structure (crystal) ensures high sensitivity to of the impact of even insignificant EMF pulses.

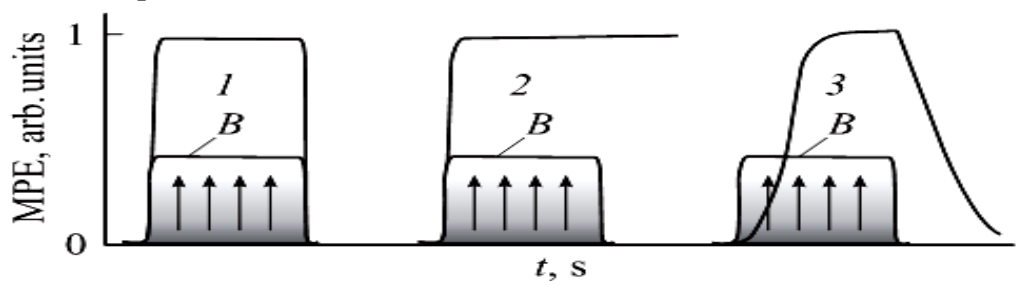

Fig. 1. Three main types of behavior of non-magnetic materials in MEP: 1 - in situ effects arising from the action of EMF, 2 - irreversible post-effects, 3 - aftereffect with slow relaxation and latent period after disconnection. 
The studies [6, 10, 13-14] describe investigations of the effect of a weak constant magnetic field on the collision of an electron on the mechanical properties of various nonmagnetic crystals $(\mathrm{NaCl}, \mathrm{CsI}$, etc.) and metals $(\mathrm{Zn}, \mathrm{Al})$. In these studies it is noted that with an increase in the exposure time of the samples in the MF, the mean dislocation path length L grew linearly; and when the temperature was varied, the path length L practically did not change. When the sign of the field is reversed, the direction of dislocation motion did not change, so the possibility of explaining the effect by the action of ponderomotive forces or a vortex electric field was excluded. Investigation of the influence of MF applied when the indenter was introduced into bismuth crystals, demonstrated increase in microhardness [15]. The opposite results were obtained for aluminum [16, 17], it was determined that exposure to a magnetic field reduces the microhardness of aluminum. It is found that creep under conditions of an external magnetic field results in a decrease in the average size of the pits of a ductile fracture by more than 2 times. Obtaining more accurate results requires improvement of the control system for high-frequency processes, however, the study confirms significant increase in the material strength.

Experimental studies of the change in the strength characteristics of samples of PA-66 polyamide in high-frequency EMF in [18] were made in accordance with regulatory requirements. After specially simulated operating conditions, corresponding to the real conditions of Western and Eastern Siberia, the samples were placed in the EMW field for a short time. The results of full-scale tests are shown in the diagrams (Fig. 2, 3). Analysis of the obtained data proves that the strength characteristics of PA-66 polyamide samples, after HF treatment, in some cases exceeded their original values. Practical implementation of restoration process of the used polyamide products is only possible in the presence of automated system of electrothermic control which depends on the automated system for sample state control.

In [19], the authors propose a method for ionizing nitriding instrumental steels in crossed electric and magnetic fields. As a result, it was found that the effect of EMF results in an increase in the microhardness by approximately 6 times.

In $[20,21]$, the authors propose a method for softening the materials of the crystal structure, which involves the action of the main and additional EMF. The achieved softening result in this case is associated with the effect of external magnetic field affects on the material containing magnetic grains (magnetite) or minerals with a piezoelectric effect (quartz). Also, because of the heterogeneity of the properties of the materials that make up the sample and the presence of water in the micropores.

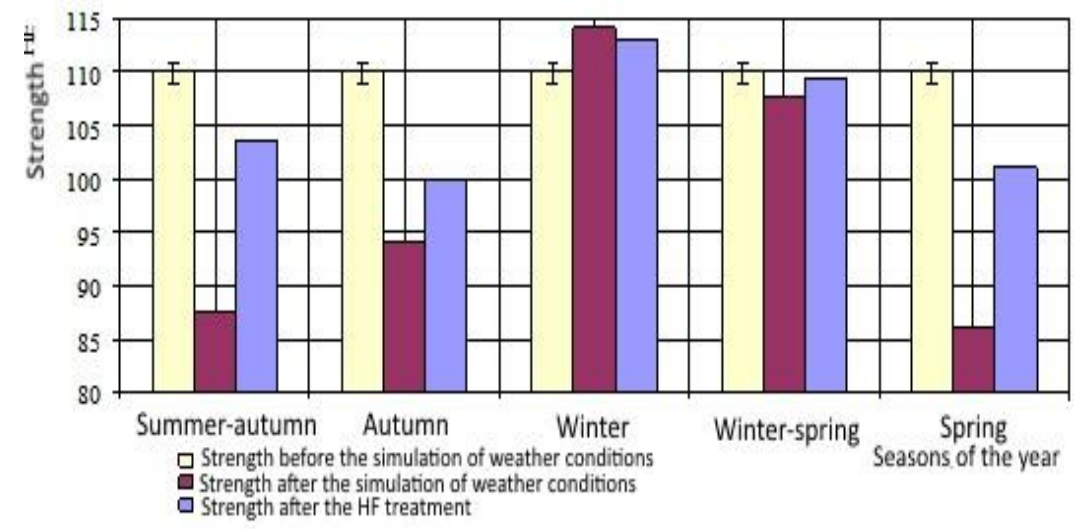

Fig. 2. Results of hardness measurements of samples. 


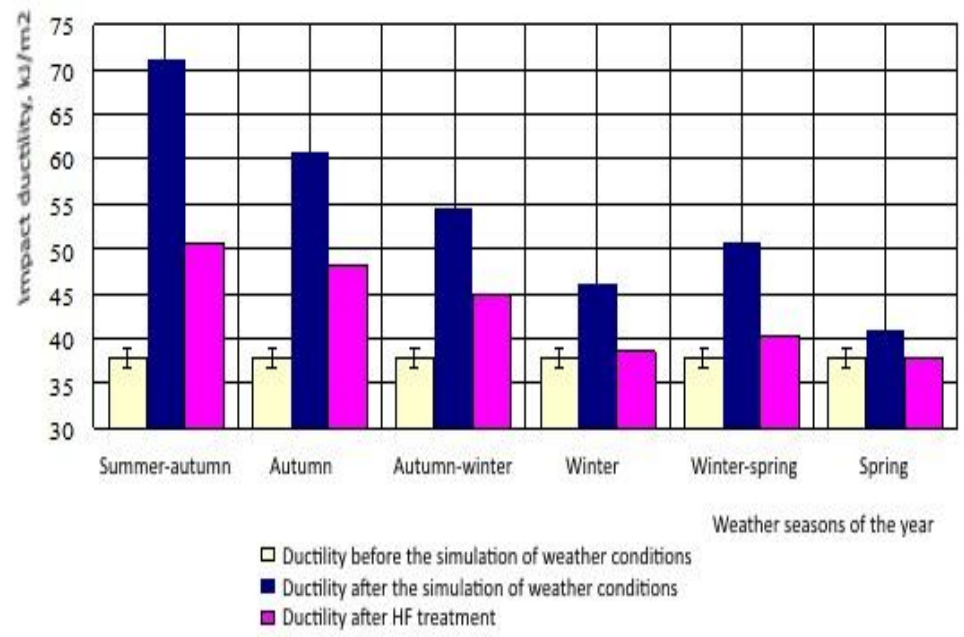

Fig. 3. Results of measurements of impact ductility of samples.

Thus, relying on the arguments of the presented papers, it can be concluded that the effect of force fields on materials is reduced to the following:

1. the given literature review demonstrates complex and multifaceted impact of EMF on various materials;

2. the emerging macroscopic effects of EMF action are the result of influence on all structural and hierarchical levels of the material;

3. threshold character of post-effects of MF effect and saturation of MPE exist;

4. MF changes the ratio of the factors that affect physical and mechanical properties in a special way;

5. EMF occurs in non-equilibrium structures;

6. there are several channels of influence of EMF on the structure and properties of the material;

7. EMF induces multistage relaxation processes of the defect structure, some of which are unique;

8. strong and weak EMF influences various objects in the material;

9. EMF causes a change in the properties of materials of different magnetic nature, which enables to use EMF treatment to modify both magnetic and nonmagnetic materials;

10. lack of automated systems for control, regulation and selection of processing modes in EMF prevents from completely solving specific scientific and production tasks and obtaining a given set of properties.

\section{Conclusion}

The results of the study prove the reality of the effects of EMF influence on the mechanical properties of many materials. This creates a foundation for a radically new highly sensitive and high-resolution method of electromagnetic spectroscopy. It was found that HF treatment, including weak and pulse one, can in some cases replace a much longer and energy-intensive heat treatment techniques. The study showed that the developed schemes and physical models of EMF impact can be applied in magnetobiology and biochemistry [22]. However, it must be mentioned that because of the lack of automated control systems for the above processes, the described techniques and methods of EMF impact presently cannot have a wide use. 
A number of studies [23-24] conducted at Irkutsk State Transport University (Russia) prove the possibility of organizing automated EMF control systems on the basis of amperometric technique. They provide algorithms of control of high-frequency electromagnetic action, both for the purpose of basic research and for a number of technological operations of treating polar construction materials (practical value).

Taking this method and control algorithms as a foundation, the topic for further study is development of a universal automated control system for EMF impact on polymer and composite materials of various nature.

\section{References}

1. Yu.A. Osipyan, S.I. Bredikhin, V.V. Kveder, N.V. Klassen, V.D. Negriy, V.F. Petrenko, I.S. Smirnova, S.A. Shevchenko, E.A. Shteynman, S.Z. Shmurak, Elektronnye svojstva dislokacij $v$ poluprovodnikah [Electronic properties of dislocations in semiconductors] (Moscow, 2010). (in Russian)

2. V.A. Lavrentyev, S.G. Kalganova, Problemy elektrojenergetiki [Problems of electric power industry], 133-136 (2008). (in Russian)

3. Yu.A. Klimov, V.M. Maslovskiy, K.V. Kholodnov, Elektronnaja tehnika [Electronics engineering], 3, 5(144), 22 (1991). (in Russian)

4. A.G. Kadmenskiy, S.G. Kadmenskiy, M.N. Levin, V.M. Maslovskiy, A.V. Chernyshev, Pisma v zhurnal tehnicheskoj fiziki [Applied Physics Letters], 19(3), 41 (1993). (in Russian)

5. M.N. Levin, Yu.O. Lichmanov, V.M. Maslovskiy, Pisma v zhurnal tehnicheskoj fiziki [Applied Physics Letters], 20(4), 27 (1994). (in Russian)

6. K.M. Salikhov, Y.N. Molin, R.A. Sagdeev, A.L. Buchachenko, Spin Polarization and Magnetic Effects in Radical Reactions (Elsevier, Amsterdam, 1984).

7. A.L. Buchachenko, R.Z. Sagdeev, K.M. Salikhov, Magnitnye $i$ spinovye jeffekty $v$ himicheskih reakcijah [Magnetic and spin effects in chemical reactions] (Nauka, Novosibirsk, 1978). (in Russian)

8. A.L. Buchachenko, Chem. Rev., 95, 7, 2507 (1995).

9. A.V. Lipchitz, A.G. Larchenko, N.G. Filippenko, Transportnaja infrastruktura Sibirskogo regiona [Transport infrastructure of the Siberian region]: Proceedings of the $5^{\text {th }}$ International scientific conference (Irkutsk, March 31 -April 4, 2014). (in Russian)

10. Yu.I. Golovin, Tambov University Reports. Series: Natural and Technical Sciences, Vol. 1, Issue 1, 3-20 (1996). (in Russian)

11. V.I. Alshic, E.V. Darinskaya, T.M. Perkalina, A.A. Urusovskaya, Physics of the Solid State, Vol. 29, 2, 467-470 (1987). (in Russian)

12. Yu.I. Golovin, Physics of the Solid State, Vol. 46, 5, 769-803 (2004). (in Russian)

13. N.I. Burlaka, Novye zadachi sovremennoj mediciny [New problems of modern medicine]: Proceedings of the III International scientific conference, 11-13 (St. Petersburg, Dec. 2014). (in Russian)

14. V.I. Alshic, E.V. Darinskaya, E.A. Petrzhik, Physics of the Solid State, Vol. 35, 2, 320-322 (1993). (in Russian)

15. Yu.I. Golovin, R.B. Morgunov, S.E. Zhulikov, Crystallography Reports, Vol. 43, 4, 689-693 (1998). (in Russian)

16. S.I. Popov, A.V. Lipchitz, N.G. Filippenko, Transportnaja infrastruktura Sibirskogo regiona [Transport infrastructure of the Siberian region]: Proceedings of the $3^{\text {rd }}$ International scientific conference, 430-437 (Irkutsk, Russia, May 13-17, 2013). (in Russian) 
17. K.N. Ramazanov, V.V. Budilov, R.K. Vafin, Strengthening technologies and coatings, 5, 39-42 (2010). (in Russian)

18. P.P. Ananyev, S.A. Goncharov, E.L. Belchenko, V.P. Stupnikov, Patent EA 003853B1 (2003). (in Russian)

19. Yu.I. Golovin, Physics of the Solid State, Vol. 46, Issue 5 (2004) (in Russian)

20. T.G. Prokhorova, S.S. Khasanov, L.V. Zorina, L.I. Buranov, V.A. Tkacheva, A.A. Baskakov, R.B. Morgunov, M. Gener, E. Canadell, R.P. Shibaeva, E.V. Yagubskii, Adv. Funct. Mater., 13, 5, 1 (2003).

21. A.V. Komshina, A.S. Pomelnikova, Nauka i Obrazovanie [Science and Education], ФС 77-48211, 09 (сентябрь, 2012). (in Russian)

22. N.G. Filippenko, A.V. Lipchitz, A.Ya. Mashovich, Modern Technologies. System Analysis. Modeling, Vol. 2 (30), 193-198 (2011). (in Russian)

23. A.V. Lipchitz, S.I. Popov, N.G. Filippenko, A.G. Larchenko, Modern Technologies. System Analysis. Modeling, Vol. 2 (38), 152-157 (2013). (in Russian)

24. A.V. Lipchitz, N.G. Filippenko, A.G. Larchenko, Modern Technologies. System Analysis. Modeling, Vol. 5, 41 (2014). (in Russian) 